\title{
Lógica da (In)apropriação? Os problemas do construtivismo na análise do alargamento da União Européia
}

\section{Logic of (In)appropriateness? The problems of constructivism in the analysis of European Union enlargement}

Fabiano Mielniczuk'

DOI: 10.5752/P.2317-773X.2019v7.n2.p7

Recebido em: 12 de junho de 2018 Aprovado em: 20 de agosto de 2018
1. Doutor em Relações Internacionais pelo IRI/PUC-Rio, é mestre em Relações Internacionais pelo mesmo Instituto e graduado em Ciências Sociais pela UFRGS. Professor do Departamento de Ciência Política da UFRGS e Colaborador dos Programas de Pós-graduação em Ciência Política e Estudos Estratégicos Internacionais. Porto Alegre/Brasil. ORCID: 0000-0002-0060-1039 (1D)

\section{Resumo:}

Muitos construtivistas na área de Integração Européia oferecem explicações sobre o processo de alargamento da UE a partir da lógica da apropriação, opondo-a a explicações baseadas na lógica da conseqüência. A primeira seria fundada em uma ontologia construtivista, indicando a prevalência das normas na determinação do comportamento dos atores. Já a segunda é associada a uma ontologia racionalista, com atores que interagem a partir de identidades pré-definidas, não constituídas pelas normas dos contextos de interação. $\mathrm{Na}$ medida em que os candidatos do leste da Europa foram incorporados ao processo de adesão, esperava-se a adequação de suas condutas às normas que conferiam identidade à União Européia. O problema é que a lógica da apropriação pressupõe a existência de normas institucionalizadas, de modo que as ações dos não-membros pudessem ser comparadas a elas e consideradas "apropriadas" ou não. Isso implica, também, que os membros da UE deveriam reproduzir em suas ações o que prescrevem para que novos candidatos fossem aceitos. Todavia, uma breve análise do trato conferido às minorias indica que essas duas condições não foram satisfeitas durante o processo de alargamento. O artigo elabora os motivos teóricos e políticos para essa inconsistência, e propõe que o modelo construtivista é inapropriado.

Palavras-Chave: Alargamento da União Européia; Construtivismo Social; Integração Européia; Condicionalidades; Lógica da Apropriação.

\section{ABSTRACT:}

Many constructivists in the field of European Integration treat the process of EU enlargement employing the logic of appropriateness as a theoretical framework, in opposition to the logic of consequences. The former is based on a constructivist ontology which asserts that norms play an important role in determining actors ' behavior. By its turn, the latter is associated to a rationalist ontology, in which actors have pre-determined identities that are by no means constituted by the context in which they interact. When states from East Europe started the process of accession, they were expected to adequate their 
behavior to the norms that confer identity to the EU. The problem is that the logic of appropriateness presupposes the existence of an institutionalized set of norms that can be contrasted to non-members actions so that they can be evaluated as appropriate or inappropriate to join the EU. It also implies that old members must follow what they prescribe as conditions to the acceptance of future members. A brief analysis of the policies toward minority rights demonstrates that these two conditions were not satisfied during the enlargement process. The paper presents theoretical and political motives for this inconsistency, and argues that the constructivist model is inappropriate.

Key-words: European Union Enlargement; Social Constructivism; European Integration; Conditionalities; Logic of Appropriateness.

Introdução

Nos estudos construtivistas sobre o alargamento europeu é bastante comum se afirmar que os atores são regidos pela lógica da apropriação em oposição à lógica da conseqüência (OLSEN; MARCH, 2004). A primeira significa aceitar que os atores agem conforme aquilo que é apropriado ao contexto de interação. Portanto, há um efeito constitutivo que parte da estrutura para a agência. Já a lógica de conseqüência pressupõe que atores com interesses pré-estabelecidos interagem com a estrutura apenas em busca da otimização dos resultados, sem que ela afete suas propriedades constitutivas. Um exemplo ilustra esse emprego.

Schimmelfennig (2002) formula a hipótese da comunidade liberal para explicar o processo de alargamento: sua probabilidade depende do grau em que os candidatos aderem aos valores e normas liberais que constituem a identidade da União. Assim é possível entender porque o processo de alargamento também é tratado como resultado de uma "armadilha comunitária." Mesmo incertos a respeito das conseqüências provenientes do alargamento, os Estados membros da UE são obrigados a aceitar o processo de expansão na medida em que alguns candidatos da Europa do Leste e Central incorporaram os valores liberais (SCHIMMELFENNIG, 2001).

Há pelo menos três problemas nessa abordagem. Em primeiro lugar, há o pressuposto de que existe uma identidade comum entre os membros da União que, em termos gerais, pode ser tratada de forma homogênea e fixa quando vista de fora. Portanto, priorizar esse enfoque implica negligenciar as tensões a respeito da própria identidade da União e a indefinição contida nos documentos oficiais que a definem. Um segundo problema, que de certo modo está associado ao anterior, se relaciona ao pressuposto de que os valores liberais aceitos como os que fundamentam a identidade coletiva da União Européia são praticados. Essa presunção desconsidera os problemas relacionados à aplicação dos critérios de condicionalidade aos candidatos a partir de um padrão duplo, visto que eles não são exigidos dos membros que já fazem parte da Organização. Por último, aceitar a lógica da apropriação implica desconsiderar os impactos dos não-membros na constituição da identidade da UE. Isso é problemático na medida em que a adoção de uma identidade pré-estabelecida para a UE limita a aplicação da teoria construtivista. 
O que proponho é problematizar o emprego desse modelo para explicar o alargamento europeu. O texto está dividido em quatro partes. Na seção 2, apresento a formulação original da lógica da apropriação e a utilização do conceito nos estudos sobre o alargamento da UE. Na seção 3, a contradição entre o discurso e a prática em relação às exigências feitas aos candidatos é tratada. Na seção 4 apresento o argumento defendendo a inapropriação da lógica da apropriação, e sugiro alguns motivos para tanto. Algumas considerações encerram o artigo.

A lógica da apropriação e o alargamento da UE

Tradicionalmente, os estudos de ciência política sobre as instituições assumem que os agentes são racionais, tomam suas decisões calculando custos e benefícios, e planejam o modo de agir de acordo com as conseqüências esperadas. A esse tipo de comportamento Olsen e March (2004) dão o nome de lógica da conseqüência. Porém, em muitos casos, a ação política não pode ser entendida nos marcos desse modelo, visto que algumas decisões se mostram contrárias aos interesses dos agentes. Isso ocorre quando o agente faz suas escolhas de acordo com o que seria mais adequado em determinado contexto institucional, e não de acordo com o cálculo instrumental. Para Olsen e March (2004), quando os indivíduos seguem esses princípios, eles agem de acordo com a lógica da apropriação.

Olsen e March (2004) formulam esses conceitos para explicar o comportamento dos indivíduos em instituições democráticas. Nesse sentido, os autores definem instituições como coleções estáveis de regras e práticas inseridas em estruturas de recursos que tornam a ação possível e estruturas de significados que explicam e justificam o comportamento dos agentes. Ao que tudo indica, a lógica da conseqüência enfatiza a dimensão institucional relacionada à estrutura de recursos, ao passo que a lógica da apropriação privilegia o trato das instituições como estrutura de significado. Isso permite reconhecer a existência das duas lógicas na ação dos agentes, mas o que define o tipo de comportamento em diferentes comunidades políticas é o grau de institucionalização das normas. Nesse sentido, a lógica da apropriação só é possível quando os agentes agem "(...) de acordo com as práticas institucionalizadas de uma coletividade, baseados na compreensão mútua e, freqüentemente, tácita, do que é verdadeiro, razoável, natural, direito e bom" (OLSEN; MARCH, 2004, p. 4). Há, portanto, a pressuposição da existência de uma identidade que vincula os indivíduos uns aos outros. Quanto mais intensa for identidade, maior a institucionalização das normas. Por conseguinte, mais os agentes seguirão as prescrições feitas por elas. Esse é o ambiente perfeito para o funcionamento da lógica da apropriação: "uma relação direta e quase automática entre normas e ação é mais provável em uma comunidade política com instituições legítimas, estáveis, bem definidas e integradas" (OLSEN; MARCH, 2004, p.7).

Aceitando-se a definição tradicional de Estado como junção entre território, governo e nação, as condições de uso da lógica da apropriação parecem restritas à aplicação dentro de suas fronteiras. Todavia, ao tratar das diferentes acepções do termo europeização, Olsen (2002) indica que 
uma das possibilidades é defini-lo em relação ao nível de desenvolvimento das instituições européias de governo. A europeização, nesse contexto, dependeria da institucionalização das normas européias. Esse movimento permite utilizar a lógica da apropriação para a análise em nível regional. Tanto é assim que a intensidade da institucionalização é medida a partir das mesmas variáveis utilizadas em nível estatal: o funcionamento de instituições de regulação, de socialização, de participação e de inclusão (OLSEN, 2002, p. 931). Embora Olsen (2002) seja cauteloso e não defenda essa definição como a mais pertinente, aceitar a relação entre europeização e institucionalização é necessário para aplicar a lógica da apropriação ao estudo da integração européia, e isso implica pressupor que a União Européia tem uma identidade 'legítima, estável e bem definida'.

Portanto, é coerente que Schimmelfennig e Sedelmeier (2002) definam o alargamento como um processo formal e gradual de institucionalização horizontal das regras e normas de uma determinada Organização. De acordo com essa definição, a institucionalização acontece na medida em que os atores passam a respeitar um padrão normativo em suas interações. Quando esse padrão é estendido a atores que originalmente não pertenciam a elas, há horizontalização. A adesão às normas e entrada na Organização é formal e decorre da adaptação dos não-membros ao padrão normativo vigente. Na prática, isso ocorre gradualmente, pela adoção dos critérios que condicionam o acesso à Organização. Segundo eles, o fator mais importante desse processo é o chamado de cultural match: o grau em que agentes de fora e de dentro da Organização compartilham a mesma identidade e as mesmas crenças. Traduzindo em termos científicos, os autores sustentam que a hipótese construtivista sobre o alargamento seria a seguinte:

\footnotetext{
The more an external state identifies with the international community that the organization represents and the more it shares the values and norms that define the purpose and the policies of the organization, the stronger the institutional ties it seeks with this organization and the more the member states are willing to pursue horizontal institutionalization with this state. (SCHIMMELFENNIG SEDELMEIER, 2002, p. 513)
}

Os autores sugerem o que uma abordagem construtivista deve esperar quando se comparam a postura dos candidatos ao ingresso na UE com a dos Estados que já são membros. De acordo com eles, há dois motivos para se esperar que os conflitos a respeito do ingresso na UE surjam com mais intensidade na política interna dos candidatos. Em primeiro lugar, a decisão de ingressar em uma Organização significa uma mudança de rumo, ao passo que para os membros as discussões acerca do alargamento podem ser entendidas como continuidade, visto que eles já fariam parte da Organização. Em segundo lugar, não haveria conflito entre os Estados membros porque se assume que eles compartilham “(...) os valores e normas constitutivos da Organização por terem sido expostos, por um período de tempo, à socialização dentro da Organização." (SCHIMMELFENNIG ;SEDELMEIER, 2002, p. 514). Há o reconhecimento de que, ao se relaxar o pressuposto de valores e normas compartilhadas, três resultados são esperados: 1) se há tensão sobre normas e valores dentro da comunidade, não haverá uma posição única sobre o alargamento; 2) a identificação com a Organização e internalização de seus valores também seriam variáveis entre os membros e, por último; 3) poderia haver 
variação das normas particulares da Organização para grupos diferentes (SCHIMMELFENNIG; SEDELMEIER, 2002). Todavia, a própria elaboração dessas alternativas a partir da flexibilização do pressuposto reforça sua existência como ponto de partida teórico para o entendimento do processo de alargamento.

Por sua vez, a preocupação com questões relacionadas à socialização é levada adiante por Checkel (1999). O autor argumenta que socialização e aprendizado são mecanismos que explicam como os agentes mudam suas propriedades de acordo com o ambiente institucional. Isso é importante, pois permite elucidar como ocorreu a europeização dos membros, e vislumbrar caminhos para o processo de institucionalização horizontal direcionada aos candidatos. O autor divide os três institucionalismos empregados no estudo da integração européia em dois grupos: o racional e o histórico estariam em conformidade com a lógica da conseqüência e o sociológico com lógica da apropriação. É no institucionalismo sociológico (construtivismo) que a socialização desempenha, junto com o aprendizado, um papel fundamental.

Aprendizado social e socialização são definidos como processos pelos quais os agentes adquirem novos interesses e preferências por intermédio da interação com contextos institucionais mais amplos. Em nível individual, e restrito ao grupo dos tomadores de decisão, quatro variáveis aumentam as chances da ocorrência de aprendizado: os indivíduos possuem o mesmo background profissional; os representantes do grupo precisam lidar com uma crise, o que abre novas possibilidades de aprender; há alta densidade de interação entre eles; os tomadores de decisão encontram-se insulados de pressão política. Deve-se considerar, também, a importância da persuasão nos processos de aprendizado. Aliás, ela consiste em mudar a percepção dos outros a respeito de relações de causa e efeito sem uso da coerção. Por sua vez, a persuasão é facilitada quando os agentes interagem em um ambiente novo, quando quem persuade pertence ao grupo que quem é persuadido pretende ingressar e quando o agente tem poucas crenças inconsistentes com as de quem o persuade (CHECKEL, 1999, p. 549-550).

A socialização também é entendida por intermédio dos processos de constituição da norma e de difusão entre os agentes, de modo que ela de fato passe a servir de referência para a ação. Três características são fundamentais para a constituição da norma: $1^{\circ}$ ) Alguns indivíduos conseguem fazer com que os outros aceitem determinados valores como válidos para todo grupo. Esses são chamados de empreendedores morais; $2^{\circ}$ ) Tais indivíduos aproveitam as janelas de oportunidade política que surgem em algumas situaçõese oferecem a solução quando o grupo enfrenta problemas; $3^{\circ}$ ) o aprofundamento da constituição das normas iniciadas pelos empreendedores morais ocorre de acordo com as práticas de aprendizado social e persuasão e são difundidas por meio da mobilização social, quando atores não-estatais e redes se unem em defesa de sua aplicação em seus Estados (CHECKEL, 1999, p. 551-553).

Os próprios construtivistas reconhecem que os resultados desses dois processos não são homogêneos para todos os países membros da União Européia, como ilustra o caso da Inglaterra (MARCUSSEN et al., 1999). 
Todavia, o modo como o problema da socialização é formulado já indica a existência do pressuposto de europeização entre esses países. Para esses autores, as identidades sociais são definidas tanto a partir de uma identificação dentro do grupo, quanto em oposição a outras identidades que estão fora. Nesse sentido, afirmam que a identidade da Inglaterra se constitui como se a Europa fosse o "outro externo." Todavia, esse processo ocorre pela afirmação de uma identidade inglesa fundada nos valores liberais e democráticos, exatamente os valores que passam a ser aceitos por alemães e franceses em seu caminho rumo à identificação com a Europa (MARCUSSEN et al., 1999). Por isso é plausível aceitar a existência de comunhão de valores entre a Inglaterra e os outros membros da União, mesmo que em graus de europeização distintos.

Risse (2004) explora esse ponto e sugere que, por ser construída por afinidade, de dentro para fora, e pela diferença, de fora para dentro, deve-se flexibilizar a idéia de uma identidade européia. Assim, haveria três maneiras de concebê-la. A primeira é aceitar que as identidades se constituem a partir de círculos concêntricos, nos quais as identidades gerais subsumem as identidades mais específicas. A esse tipo de identificação, o autor dá o nome de "nested identities". Ela é ilustrada a partir de uma analogia com as bonecas russas: existe um "core" identitário e outras identidades que se afastam desse centro. Como se a boneca que estivesse no centro representasse a identidade mais forte, e as demais representassem outras identidades, não tão fortes quanto à primeira, mas igualmente importantes. Dessa forma, identidades diferentes não são excludentes, mas complementares. Esse é o caso de pessoas que alegam maior identificação com suas nações e depois com a Europa. A segunda forma é chamada de "cross-cutting identities," que implica que os indivíduos podem se identificar com grupos diferentes, sem que haja a sobreposição do caso anterior. Um terceiro modo de tratar as identidades é a partir da afirmação de que é impossível separar identidades coletivas de identidades individuais e que se deve levar em consideração que todos se constituem mutuamente. Esse seria o modelo do "marble cake" (RISSE, 2004, p.168-169).

Parece contraditório, mas a idéia de que os membros da União Européia comungam de uma mesma identidade só pode ser sustentada a partir da afirmação de que existem múltiplas identidades, pois apenas dessa maneira é possível reconhecer as diferenças entre eles. É como se existisse uma identidade que servisse como ponto de referência a todas as outras. A partir dessa constatação, faz sentido afirmar que a UE é definida a partir de uma identidade coletiva liberal, fundada na crença à adesão aos direitos humanos. No âmbito doméstico, essa identidade se traduz no respeito à propriedade privada e às regras de mercado, na prática da democracia política representativa, na aceitação do pluralismo e na vigência do Estado de direito. No âmbito internacional, a identidade liberal indica que os Estados não farão guerras uns com os outros e que o multilateralismo será favorecido. Os Estados candidatos cujas práticas políticas permitem a identificação a essas normas têm mais probabilidade de ingressar na UE do que os outros (SCHIMMELFENNIG, 2001).

Com base nessa avaliação é formulada a hipótese da comunidade liberal para explicar o alargamento. De acordo com ela, 
(...) the more a state adheres to these norms, the more likely it is that it enters into institutionalized relations with, applies for membership in, and is admitted to these organizations. Conversely, associated or member states that violate these liberal norms will systematically be excluded or withdraw from the organizations. (SCHIMMELFENNIG, 2002, p. 598-599)

A referida hipótese é testada com o emprego da análise histórica de eventos. Isso é feito pela análise de quatro eventos relacionados ao processo de alargamento: a institucionalização das relações entre um Estado candidato e a Organização, o início formal da candidatura, o acesso à Organização e, por último, seu possível desligamento. As principais variáveis utilizadas pelo autor são: POLITY, que mede a grau de adesão a normas democráticas; MIDS, a qual indica o respeito às normas de administração pacífica de disputas entre Estados e; NEUTR, uma variável que indica se os Estados são neutros ou não, como forma de inferir o grau de participação política nas esferas multilaterais. Considerando-se as variáveis de controle e os demais indicadores utilizados na análise, pode-se supor que se o valor de POLITY for alto, o de MIDS for baixo e o de NEUTR não for significativo, é mais provável que o Estado comece negociações de acesso que sejam bem sucedidas, sem que haja o risco de desligamento. Após a análise dos dados, conclui-se que apenas a POLITY é fortemente correlacionada ao processo. Esse resultado permite afirmar que, mesmo sendo corroborada parcialmente pela análise, a hipótese da comunidade liberal é adequada para explicar o alargamento: se os valores liberais se restringirem à prática política dentro do Estado candidato (SCHIMMELFENNIG, 2002).

Afirmar a correlação entre valores liberais dos candidatos e o processo de alargamento não indica as causas que o impulsionam. Segundo Schimmelfennig (2001), o que está por trás dessa lógica é a ação retórica de alguns Estados membros que são favoráveis ao processo de expansão. Aliando seus interesses ao padrão de legitimidade estabelecido pelas normas que conferem identidade à Organização, esses Estados criam uma armadilha para os membros que são contrários ao alargamento: os que são a favor acusam os que são contra de, ao negar acesso aos candidatos do centro e leste da Europa, negar a própria identidade, uma vez que muitos entre os que desejam ingresso já haviam incorporado o liberalismo político e a economia de mercado em suas práticas políticas domésticas. A obediência aos padrões de legitimidade é garantida pela ameaça de desmoralização dos membros que caírem em contradição defendendo seus interesses particulares em detrimento da identidade coletiva. Esse é o mecanismo que explica o avanço do alargamento (SCHIMMELFENNIG, 2002, p. 62-65; RISSE, 2004, p. 172-173).

Resulta que a ação retórica é definida como o uso estratégico de argumentos baseados nas normas que definem a identidade da Organização por Estados que buscam maximizar seus interesses. Desse modo, a prática da ação retórica pressupõe a existência de mais liberdade dos agentes em relação à estrutura, o que significa relaxar as condições ideais para a existência da lógica da apropriação, conforme enunciadas por Olsen e March (2004). Todavia, esse movimento está inteiramente de acordo com a existência de níveis de europeização distintos entre os agentes, e com a afirmação de que os agentes possuem múltiplas identidades que têm como referência a identidade coletiva européia. Aliás, a própria prática da 
ação retórica reforça a identidade social européia, pois conduz os agentes a observar os padrões de legitimidade derivados das normas que a constituem. Desse modo, o pressuposto de uma identidade prévia entre os membros da União Européia, necessário para a aplicação da lógica da apropriação ao alargamento, permanece válido.

Alargamento na prática: dois pesos, duas medidas

$\mathrm{Na}$ prática, o processo de alargamento ocorreu de acordo com a aplicação de condicionalidades: arranjos mútuos nos quais um governo toma, ou promete tomar, determinadas decisões em relação a políticas públicas (CHECKEL, 2000). No caso da União Européia, ela é o conjunto de políticas públicas que devem ser implementadas pelos candidatos como pré-condição necessária ao ingresso na Organização (Idem). Os primeiros critérios de acesso foram elaborados durante a Cúpula de Copenhague, em 1993. Eles refletem a tentativa de reduzir os riscos de instabilidade política e de gastos excessivos que a entrada de novos membros poderia acarretar, bem como de garantir o cumprimento das leis européias, a fim de assegurar aos membros contrários ao alargamento que os problemas decorrentes do processo seriam mínimos (GRABBE, 2002, p.251). Posteriormente, em 1998, é lançado o programa de "Parcerias de Acesso," o qual detalha com precisão, por intermédio de listas específicas feitas para cada candidato, quais melhorias são necessárias em suas instituições para se alcançar os critérios de Copenhague. Em 2000, entram em vigor as decisões tomadas em 1999, na Cúpula de Helsinque, que admitem diferentes velocidades para os processos de ingresso: os candidatos que mais se adequassem à condicionalidade chegariam primeiro à UE (CHECKEL, 2000; GRABBE, 2002).

Como era de se esperar, as três condições estabelecidas em Copenhague estão em conformidade com a descrição da identidade coletiva da União Européia feita pelos adeptos da lógica da apropriação para explicar o alargamento (RISSE, 2004; SCHIMMELFENNIG, 2001; SCHIMMELFENNIG E SEDELMEIER, 2002). A primeira delas versa sobre os valores do liberalismo político, ao prescrever que os candidatos devam possuir instituições estáveis que garantam a democracia, o Estado de direito, os direitos humanos e o respeito e proteção às minorias. A segunda trata dos princípios do liberalismo econômico, na medida em que impõe a existência de economia de mercado e capacidade competitiva em relação aos outros membros. A terceira condição exige a adesão aos objetivos de unificação política, econômica e monetária do bloco, que implica o respeito ao acquis comunnautaire (GRABBE, 2002). Com o avanço nas negociações específicas de acesso, as condicionalidades passaram a incluir o fortalecimento da capacidade estatal, a independência do judiciário, o combate à corrupção, igualdade de gênero, combate ao tráfico de mulheres e crianças, entre outras (PRIDHAM, 2006, p.380). Essas medidas apenas complementam a identidade da União Européia, visto que elas são necessárias para garantir a vigência de uma ordem política liberal.

Embora sejam aplicadas aos candidatos, tais especificações podem ser entendidas como tentativas de refinar a definição da identidade da 
União Européia, uma vez que derivam dos valores compartilhados pelos membros. Mesmo assim, a falta de clareza na política de condicionalidade é bastante criticada, e reflete própria ambigüidade da identidade da União. Para uns, elas “(...) têm sido administradas pragmaticamente e desenvolvidas sem o envolvimento de qualquer visão sobre a democracia liberal (PRIDHAM, 2006, p.381). Para outros, "a União Européia não apresenta um modelo uniforme de democracia ou capitalismo, e nem sequer tentou definir um" (GRABBE, 2002, p.250). Essa ponderação é relevante na medida em que ameaça a efetividade da política de condicionalidade, uma vez que existem opções diferentes para os candidatos no momento de pôr em prática as políticas públicas voltadas para o atendimento aos critérios de Copenhague. O problema que surge, então, é saber quais são os padrões mínimos aceitos pela União. Nas palavras do mesmo crítico citado acima: "Os novos membros precisam de uma economia alemã, um serviço civil britânico, um estado de bem-estar sueco e um sistema eleitoral francês? Ou uma economia grega, um serviço civil belga, relações industriais austríacas e um sistema eleitoral italiano?"(GRABBE, 2002, p.250).

Outro problema é que a União Européia exige dos candidatos muito mais do que cobra de seus membros. Existe um ressentimento por parte dos candidatos devido à constatação de que alguns membros antigos da União Européia não seriam aprovados para o ingresso na Organização caso tentassem suas candidaturas no final dos anos 1990. Essa polêmica se relaciona, principalmente, à figura de Sílvio Berlusconi, o qual possui um vasto histórico de acusações sobre corrupção e, enquanto no poder como primeiro-ministro italiano, mostra-se um político decidido a aprovar leis que favoreçam seus interesses privados. Além disso, o simples fato de um líder político ser dono de importantes veículos de comunicação em um país democrático já é o suficiente para colocar em questão o quão democráticas são suas instituição políticas. Segundo Pridham, "(.) a questão é que os registros atuais e o comportamento de alguns membros estão em conflito com os valores das políticas da UE como elas vêm sendo desenvolvidas desde meados dos anos 1990" (2006, p.392).

A incoerência também é evidenciada pela adoção dos critérios de Copenhague (1993) no Tratado de Amsterdã (1997) sem referência à proteção do direito das minorias (SASSE, 2005; KEATING, 2004). A ausência de fundamento jurídico comum entre os membros sobre o assunto, a falta de prioridade dada aos problemas dessa natureza até que eles começassem a surgir no pós-guerra fria, ou até mesmo a complexidade de definir o que é uma minoria no âmbito do direito internacional são algumas razões para o "esquecimento." Nesse sentido, não causa estranheza o fato de os parâmetros para compreensão dos "direitos das minorias" serem procurados pelos funcionários encarregados de acompanhar a implementação dos critérios de Copenhague em resoluções das Nações Unidas, em documentos da OCSE e na Convenção Quadro para Proteção de Minorias Nacionais do Conselho da Europa (CQPMN), de 1995. Ironicamente, mesmo que França, Bélgica, Holanda, e outros membros não tivessem ratificado a CQPMN, os funcionários recomendavam que os candidatos sob escrutínio o fizessem (SASSE, 2005, p. 3-5). A contradição ilustra a existência de uma lógica de "dois pesos, duas medidas", que consistia na prescrição de 
receitas de como os candidatos deveriam tratar as minorias, mesmo que a prescrição não fosse seguida pelos membros. O reconhecimento de que os relatórios eram formulados em comparação a um "membro perfeito," ou a consciência de que o pior caso de desrespeito às minorias entre os atuais membros da UE seria o suficiente para desqualificar a candidatura de um não-membro, são indícios de que os funcionários reconheciam a inconsistência (SASSE, 2005, p.10-12).

Johns (2003) reforça o argumento sobre a existência de dois padrões para as minorias ao comparar o modo como a Letônia trata os russos e a Eslováquia os húngaros e ciganos (roma), com a maneira como a Itália trata os ciganos e a Alemanha os turcos. Depois da II Guerra Mundial, os russos foram se estabelecendo no Báltico como resultado da política de sovietização implementada por Stálin. Logo após o fim da URSS, havia uma grande minoria russa no país. Imediatamente, o governo da Letônia aprova uma série de leis que restringem os direitos dos russos à propriedade, a se candidatarem em eleições, a ocuparem cargos públicos, etc., seguindo o princípio de que apenas a nacionalidade dominante teria direito à cidadania. Essa política foi duramente criticada pelo Alto Comissariado sobre Minorias Nacionais (ACMN) da OCSE e pelos relatórios anuais da UE sobre o cumprimento dos Acordos Europeus, como eram chamados os acordos firmados no âmbito do programa Parceria para Acesso. O mesmo ocorre com a Eslováquia, que discrimina húngaros e ciganos em sua legislação sobre o ensino da língua nacional. No caso específico dos ciganos, há problemas com a educação das crianças, discriminação em relação ao mercado de trabalho e, freqüentemente, o grupo é vítima da violência policial e de ataques de skinheads.

Johns (2003) argumenta que a situação das minorias em alguns países da União Europeia não diferia muito da situação na Letônia e na Eslováquia, mas que mesmo assim nenhuma recomendação e/ou admoestação foi apresentada pelo ACMN. O caso da Alemanha pode ser comparado ao da Letônia. Na Alemanha, os turcos se estabeleceram na década de 1950 para realizar trabalhos menos valorizados para os quais não havia mão-de-obra disponível. Hoje, muitos turcos que nasceram na Alemanha, falam alemão, e já perderam os laços com a Turquia, continuam sendo tratados como estrangeiros, e não têm acesso à cidadania alemã, também baseada na nacionalidade dominante. Os turcos sofrem restrições para votar, para arranjar emprego e podem ser expulsos do país por viverem em situação clandestina. Na Itália, os ciganos são vítimas de violência policial, às vezes relacionada à violência sexual contra as mulheres. Também há dificuldade em conseguir emprego e até a liberdade de movimento é restrita, havendo locais específicos (campos) onde eles podem viver. Uma análise estatística sobre a situação das minorias na Europa indica que o grau de discriminação sofrido nos países ocidentais é superior aos níveis praticados nos países da Europa Central e do Leste (JOHNS, 2003, p.690-696).

O que há de inapropriado nisso?

Sending (2002) argumenta que a lógica da apropriação não atende às demandas ontológicas de uma versão moderada de construtivismo. Para o autor, o construtivismo via media está assentado sobre três 
pressupostos, a saber: de que as normas constituem os agentes, de que agente e estrutura são co-constituídos e de que as mudanças nas estruturas ideacionais levam a mudanças nas práticas políticas dos agentes. Desses três pressupostos, apenas o primeiro seria atendido integralmente pela lógica da apropriação, devido ao caráter comunitarista subjacente a sua formulação. Tal comunitarismo é o reflexo da compreensão de que as relações sociais estão baseadas em uma idéia de bem comum, e no trato das normas como constitutivas da realidade social. A instituição seria a sedimentação dessas normas em padrões estáveis de comportamento. Desse modo, as instituições definem as perspectivas normativas e cognitivas pelas quais os agentes de uma dada comunidade política tomam suas decisões. É correto, portanto, afirmar que as normas constituem os agentes. Esse é o argumento teórico que sustenta as instituições como variáveis causais, e não intervenientes (SENDING, 2002, p. 446-447- 452).

Sobra, então, pouca margem de manobra para a ação individual, pois a própria interpretação das situações sociais que os agentes enfrentam é limitada pelo caráter constitutivo das normas, entendidas sob a ótica comunitarista. Esse aspecto limita a abordagem da lógica da apropriação no que diz respeito à co-constituição entre agente e estrutura, uma vez que a motivação para agência parte da própria estrutura, como se ela exercesse uma autoridade objetiva sobre o agente, algo chamado de posição motivacional internalista (SENDING, 2002, p.453-459). Tendo isso em vista, as mudanças nas normas seriam impossíveis se os atores continuassem reiteradamente se comportando de modo apropriado e reproduzindo-as por intermédio dessas práticas sociais. Portanto, os teóricos que adotam a lógica da apropriação explicam as transformações na estrutura social pela agência inapropriada, ou seja, fora dos padrões estabelecidos pelas normas vigentes (SENDING, 2002, p. 459-460). Os agentes que agem dessa forma são os empreendedores morais discutidos na seção 2. A necessidade de recorrer a essa explicação invalida a relação dessa abordagem com o terceiro pressuposto construtivista.

Se essas observações estão corretas, a lógica da apropriação é inapropriada para explicar o processo do alargamento por dois motivos. Em primeiro lugar, porque não há uma definição clara da identidade da União Européia (PRIDHAM, 2006; GRABBE, 2002). Isso ocorre porque suas normas ainda não se europeizaram a ponto de exercerem autoridade objetiva sobre os agentes, o que resultaria no comportamento uniforme dos mesmos. Todavia, os construtivistas acreditam que as normas constituem a identidade européia. Por mais que Schimmelfennig (2001) confira mais "liberdade instrumental" aos agentes, a ação retórica utilizada por eles para alcançar seus interesses é praticada no âmbito das normas e, ao fim do processo, acaba por reforçá-las. Por mais que Risse (2004) tente flexibilizá-las, a afirmação de que existem múltiplas identidades é inócua nesse sentido, pois a identidade européia ainda permanece como ponto de referência para a mensuração da distância entre as outras identidades (a escala parte das identidades subnacionais para as nacionais, passando pelas sub-regionais e, finalmente, chegando à identidade européia). O argumento que sustento é simples: se as normas a constituíssem, haveria clareza a respeito da definição da identidade européia. Como esse fenômeno 
não se comprova empiricamente, o emprego é inapropriado. Isso não significa negar a possibilidade teórica do uso da lógica da apropriação pelos construtivistas em relação ao pressuposto das normas que constituem os agentes, conforme aceito por Sending (2002). Afirmo apenas que ela não se mantém empiricamente para explicar a identidade da União Européia.

$\mathrm{Na}$ ausência de uma identidade européia real, os construtivistas empregam uma identidade européia desejada como ponto de partida para explicar o alargamento. A política de dois pesos, duas medidas utilizada na aplicação das condicionalidades é o reflexo dessa situação, e essa contradição invalida completamente o emprego da lógica da apropriação. Afinal, como é possível afirmar que as normas constituem os agentes se os agentes não fazem na prática o que elas prescrevem? De fato, a contradição é negligenciada, e o esquecimento desse problema é mantido por intermédio da subvalorização dos impactos dos não-membros na constituição da identidade da UE e da conseqüente valorização dos impactos da UE nos não-membros. Aliás, essa é preocupação primordial dos estudos sobre condicionalidade (CHECKEL, 2000; SCHIMMELFENNIG; SEDELMEIER, 2004). Os construtivistas só não deixam claro o porquê dessa preferência. Todavia, acredito que não reconhecer o caminho inverso é necessário para manter o fundamento da lógica da apropriação: os impactos para a UE são mínimos, uma vez que se houvesse mudança, não seria possível estabelecer a identidade de normas necessária para explicar o processo de alargamento. Há dois problemas nisso. O primeiro é que pressupõe uma identidade que não existe (ou que é desejada), visto que os agentes não agem em conformidade com ela; o segundo é que tenta esconder a inexistência dessa identidade negando as evidências empíricas de que, seja lá o que constitua a idéia de União Européia, essa idéia está sendo afetada pelos não-membros. Aceitar essa fluidez implica aceitar a inexistência daquilo que, de fato, não existe: um fundamento para explicar o processo de alargamento a partir da lógica da apropriação. Assim, a pergunta implícita nos estudos de alargamento (para onde vai à União Européia?) deixaria de fazer sentido, uma vez que não haveria ponto de partida. Esse é o segundo motivo pelo essa abordagem pode ser considerada inapropriada.

Considerações Finais

As críticas formuladas ao emprego da lógica da apropriação foram feitas a partir de uma perspectiva pós-estruturalista. Nesse sentido, o principal objetivo é denunciar a inexistência de um fundamento como referência para a aplicação dessa abordagem, desnudando o caráter contingente e fluido de uma suposta identidade européia que, reproduzida pelos países da Europa Central e do Leste, lhes garantiria o ingresso na Organização. Nessa perspectiva, a identidade européia é vista como fruto da imposição de um discurso que pretende subsumir a diferença, e que é reproduzido tanto pelas práticas políticas, como demonstra o "desejo de identidade" utilizado como referência para as políticas de condicionalidade, quanto pelas práticas acadêmicas, cujo exemplo é a aceitação da hipótese da comunidade liberal para compreender o processo de alargamento. Note-se que a aceitação da formulação acadêmica implica a negligência do problema político. Adotando uma postura de não se- 
parar a prática política da prática acadêmica, é possível perceber as consequiências normativas que decorrem do modo como se estuda a União Européia.

Nesse sentido, o próprio nome conferido a esse campo de estudos, Integração Européia, estaria sujeito à análise. A idéia de integração indica um processo. Algo que se move em alguma direção. Como Walker (2000, p.14) ressalta, o termo indica tanto um processo de crescimento em tamanho quanto de evolução em termos de progresso. Inicialmente, os discursos políticos e os acadêmicos comungavam de um mesmo ponto de partida: a Europa depois da II Guerra. Hoje em dia, as discussões estão mais voltadas para um suposto ponto de chegada. Esse ponto de chegada pode ser medido tanto em relação ao tamanho, quanto em termos dos valores que servirão de amálgama aos seus membros. Tratar de Integração Européia em debates acadêmicos e não compactuar com esse pressuposto é impossível, pois abandoná-lo significa abandonar a área de integração. A força normativa por trás dos estudos de integração é evidenciada quando se questiona a inexistência, na academia, de uma disciplina chamada Desintegração Européia. O desconforto que acomete quem pensa nesses termos é um indicador seguro de como a política de integração atua nos discursos acadêmicos sobre o tema. Pensar diferente é impensável; mesmo para quem acredita que a realidade é socialmente construída.

Os acontecimentos da última década na Europa parecem demonstrar que a inexorabilidade presente nas narrativas construtivistas sobre o processo de integração não se sustenta. Após a rodada de alargamento de 2004, a aceitação condicional da Romênia e da Bulgária, em 2007, e o ingresso da Croácia, em 2013, o processo de alargamento alcançou seu limite. A crise dos refugiados enfrentada pelo continente nos anos de 2014-2015 reforçou narrativas nacionalistas e xenófobas, as quais contribuíram para a aprovação do plebiscito do BREXIT, em 2016. Ao que tudo indica, o wishful thinking dos construtivistas cujas contribuições foram criticadas nesse artigo passa por um choque de realidade. Como resultado, a falta de ajustamento entre seus postulados teóricos e a realidade empírica força-os a uma revisão. É sintomático, nesse sentido, que os últimos estudos construtivistas sobre o alargamento europeu tenham abandonado o tratamento mais assertivo sobre a identidade europeia e adotado o conceito de "capacidade de integração", ou seja, a habilidade de preparar os futuros membros para o alargamento de modo que o funcionamento e a coesão interna da UE sejam preservados após o ingresso (BÖRZEL; DIMITROVA; SCHIMMELFENNIG, 2017).

Essas mudanças teóricas e empíricas tornam oportunos vários questionamentos. Até que ponto o modo como a Europa é pensada é condicionado por fatores políticos que limitam a percepção sobre a realidade? Por que não olhar para a Europa e enxergar agrupamentos humanos que interagem sem uma direção, sem identidades fixas, mas com identidades que se constroem e se reconstroem diariamente em um esforço contínuo para praticar o respeito à diferença? Dessa perspectiva crítica, é mais cômodo precisar o que foi pretendido nesse artigo: questionar a necessidade de um fundamento, reforçado pelos construtivistas a partir da lógica da apropriação, para que o processo de integração continue seu curso. Por isso a crítica ao construtivismo que se apropria de uma identidade européia, inexistente de acordo com as necessidades ontológicas da lógica da apropriação, para transformá-la no motor do processo de integração. 
Referências

BÖRZEL, Tanja A. , DIMITROVA, Antoaneta, SCHIMMELFENNIG, Frank. European Union enlargement and integration capacity: concepts, findings, and policy implications. Journal of European Public Policy, vol. 24, no. 2, pp. 157-176, 2017.

CHECKEL, Jeffrey T., Compliance and Conditionality. ARENA Working Papers Series, no. $18,2000$.

CHECKEL, Jeffrey T., "Social Construction and Integration". Journal of European Public Policy, vol. 6, no. 4, pp. 545-60, 1999.

GRABBE, Heather. "European Union Conditionality and the 'Acquis Communautaire'”. International Political Science Review / Revue internationale de science politique, vol. 23, no. 3, pp. 249-268, 2002.

JOHNS, Michael. "'Do as I Say, Not as I Do': The European Union, Eastern Europe and Minority Rights”. East European Politics and Societies, vol. 17, no. 4, pp. 682-699, 2003.

KEATING, Michael. "European Integration and the Nationalities Question". Politics \& Society, vol. 32, no. 3, pp. 367-388, 2004.

MARCUSSEN, Martin; RISSE, Thomas; ENGELMANN-MARTIN, Daniela; KNOPF, Hans Joachim; ROSCHER, Klaus. "Constructing Europe? The evolution of French, British and German nation state identities". Journal of European Public Policy (Special Issue), vol. 6, no. 4, pp. 614-633, 1999

OLSEN, Johan P.; MARCH, James G. "The logic of appropriateness". ARENA Working Paper Series, no. 09, pp.1-28, 2004.

OLSEN, Johan P. “The Many Faces of Europeanization”. Journal of Common Market Studies, vol. 40, no.5, pp. 921-952, 2002.

PRIDHAM, Geoffrey. "European Union Accession Dynamics and Democratization in Central and Eastern Europe: Past and Future Perspectives". Government and Opposition, vol. 41, no. 3, pp. 373-400, 2006.

RISSE, Thomas. "Social Constructivism and European Integration". In: Weiner e Diez (Orgs). European Integration Theory. Oxford: Oxford University Press, pp. 162-176, 2004.

SASSE, Gwendolyn. "EU Conditionality and Minority Rights: Translating the Copenhagen Criterion into Policy”. European University Institute Working Papers Series Robert Schuman Centre for Advanced Studies, no 16, pp. 1-21, 2005.

SCHIMMELFENNIG, Frank. "The Community Trap: Liberal Norms, Rhetorical Action, and the Eastern Enlargement of the European Union”. International Organization, vol. 55, no. 1, pp. 47-80, 2001.

SCHIMMELFENNIG, Frank. "Liberal community and enlargement: an event history analysis". Journal of European Public Policy, vol. 9, no. 4, pp. 598-626, 2002.

SCHIMMELFENNIG, Frank; SEDELMEIER, Ulrich. "Governance by conditionality: EU rule transfer to the candidate countries of Central and Eastern Europe". Journal of European Public Policy, vol.11, no. 4, pp. 661-679, 2004.

SCHIMMELFENNIG, Frank; SEDELMEIER, Ulrich. "Theorizing EU enlargement: research focus, hypotheses, and the state of research". Journal of European Public Policy, vol. 9, no. 4, pp. 500-528, 2002

SENDING, Ole J. "Constitution, Choice and Change: Problems with the 'Logic of Appropriateness' and its Use in Constructivist Theory". European Journal of International Relations, vol. 8, no. 4, pp. 443-470, 2002.

WALKER, R.B.J. "Europe is not where it is supposed to be". In: KELSTRUP, M; WILLIANS, M. (Orgs.) International Relations Theory and the Politics of European Integration: Power, Security and Community. London: Routledge, pp. 14-32, 2000. 